\title{
Examining the Necessity of Proctoring Online Exams
}

\author{
Timothy H. Reisenwitz \\ Valdosta State University
}

This study investigated the differences between non-proctored and proctored online exam scores. Exam scores of the same class from two consecutive semesters were compared. Exam averages were compared to assess if there were significant differences between the two sections, controlling for student GPA. Results support the necessity for proctored exams.

Keywords: online exams, proctored exams, non-proctored exams, academic dishonesty

\section{LITERATURE REVIEW}

Academic dishonesty, or cheating, has been a long-standing concern of academicians (Simpson \& $\mathrm{Yu}, 2012)$. Recently, academic dishonesty for online courses has been in the spotlight, largely due to the dramatic increase in the number of online courses offered at post-secondary institutions and the inherent opportunities for academic dishonesty that online courses provide students. These opportunities for academic dishonesty include identification of the student taking an exam, students collaborating on individual assessments (Harmon \& Lambrinos, 2008), and students using sources during exams that are prohibited, e.g., using notes and/or the textbook during a closed-book exam. Moreover, Jones (2011) contends that Internet plagiarism in on the rise as one of the most common forms of academic dishonesty.

\section{Addressing Academic Dishonesty}

There are various options for addressing academic dishonesty. Some institutions have implemented student conduct or honor codes in an effort to address the increasing amount of academic dishonesty. These schools contend that they experience less cheating than in schools that have not adopted such policies. Furthermore, students are more likely to report academic dishonesty by their peers than in institutions that do not have honor codes (Jones, 2009). Since online students may be from any location, honor codes may not be a successful way to address cheating. An alternative method to honor codes is requiring an authenticity statement, in which the student verifies that the work is his or hers.

Interestingly, some students do not understand what cheating is. A clear definition of academic dishonesty and its consequences should be established at the university, college, and instructor levels. After that, using technology to detect academic dishonesty is justified (Jones, 2009). There are various methods for detecting online cheating, but perhaps the best method is virtual proctoring (Porter, 2015). There are multiple examples of software available, including Remote Proctor Now (RPNow) and ProctorU. Most require a computer webcam and an Internet connection. Additionally, the online class can be redesigned to include randomized questions as well as randomized answers for those questions (Jones, 
2009; Porter, 2015). Making each test unique using large pools of questions and random generating each test will reduce or eliminate the probability of asking students the same questions.

There is little in the academic literature that has assessed whether online class exams should be proctored to prevent or minimize academic dishonesty. Studies that address this issue are Harmon and Lambrinos (2008) and Karim, Kaminsky, and Behrend (2014). Each study concludes that cheating occurred to a lesser degree when online exams were proctored. In the Harmon and Lambrinos (2008) study, the authors used two online courses to estimate a model to predict exam scores. In one course, the final exam was proctored, in the other course, the final exam was not proctored. The first exams in both courses were non-proctored. If cheating occurred in the non-proctored exam, then the explanatory power would be lower. The findings concluded that cheating occurred for exams that were not proctored.

In the Karim, Kaminsky, and Behrend (2014) study, students were randomly assigned to either a webcam/proctored or honor code condition and asked to complete two cognitive ability tests online. Cheating was determined by examining patterns of test-score differences across the two treatments. Remote proctoring resulted in less cheating. In a related study by Grijalva, Nowell, and Kerkvliet (2006), academic dishonesty was no more prevalent in online classes than it was in face-to-face or traditional classes. However, the data were from a questionnaire administered to students who had taken an online class during a particular semester. It did not examine the proctored versus non-proctored issue.

\section{Purpose of the Study and Research Question}

The purpose of this study is to investigate the value of a proctored versus non-proctored testing environment for online class exams. There are generally two views toward the use of proctors for online class exams. On one hand, proctored testing is necessary for online class exams due to the ease of academic dishonesty, or cheating, in a non-proctored online environment. On the other hand, with adjustments in course format to accommodate the online environment, such as randomized questions and time constraints, the probability of academic dishonesty can be reduced to that of a proctored situation (Harmon \& Lambrinos, 2008). Therefore, proctored exams are unnecessary.

If results in this study show that there is a significant drop in test scores from non-proctored online exams to proctored online exams, then this study would provide support for the contention that proctored tests are necessary in an online class environment. Conversely, if there are no significant differences between non-proctored online exams and proctored online exams, then this study would provide support for the contention that adjustments in course format to accommodate the online environment are sufficient to address the issue of academic dishonesty. Based upon the previous discussion and using exam data from two online classes, one non-proctored, the other proctored, the research question proposed for this study is as follows:

Research Statement: The average scores for the non-proctored online exams will be significantly greater than the average scores for the proctored online exams.

\section{METHODOLOGY}

Exam data from two online introduction to marketing courses were used in this study. The data consisted of test scores for five exams (four exams and a comprehensive final exam) in two online sections of the same course which were offered in consecutive (fall, spring) semesters. There were 40 students enrolled in this first course who received non-proctored exams. There were 33 students enrolled in the course in the following semester. The sample sizes are sufficient for analysis, since it is noted that a sample size of "at least 20 can be expected to provide very good results even if the populations are not normal" (Anderson, Sweeney, \& Williams, 2009, p. 390). All aspects of the course for both sections were identical: the instructor, the textbook, and the course format, which consisted of chapter discussion questions, chapter quizzes, and exams.

Exam questions for both sections were randomized and the answers for the exam questions were randomized, in addition to exam times limited to one hour, all to address the rationale that randomizing 
exam questions and time constraints are viable alternatives to proctoring the exam. The only difference between sections was that there was no proctoring for all exams in the fall semester class whereas all exams were proctored in the spring semester's class. Students in the proctored class had the option of using the on-campus testing center or the remote proctoring software (ProctorU). Student GPA was controlled as a covariate. It should be noted that there were two instances of cheating in the proctored exam class which resulted in zeros for the respective exams. One student was detected cheating by the ProctorU monitor during Exam 3; another student changed the dates of service in a medical excuse he submitted for missing Exam 2.

\section{ANALYSIS AND RESULTS}

The data were first analyzed via t-tests to assess the direction of the means between the non-proctored and proctored exams. The means and standard deviations are illustrated in Table 1. All means were in the hypothesized direction, i.e., the non-proctored exam means were higher than the proctored exam means for each of the five exams.

TABLE 1

\section{T-TESTS WITH MEANS AND STANDARD DEVIATIONS FOR NON-PROCTORED (NP) AND PROCTORED (P) EXAMS}

\begin{tabular}{llll}
\hline Exam & n & Mean & $\begin{array}{l}\text { Standard } \\
\text { Deviation }\end{array}$ \\
\hline Exam 1 NP & 40 & 82.35 & 25.71 \\
Exam 1 P & 32 & 59.75 & 4.47 \\
Exam 2 NP & & & \\
Exam 2 P & 40 & 78.95 & 27.76 \\
& 32 & 65.56 & 23.63 \\
Exam 3 NP & & & \\
Exam 3 P & 40 & 71.40 & 39.72 \\
& 32 & 65.12 & 24.49 \\
Exam 4 NP & & & \\
Exam 4 P & 40 & 86.10 & 25.34 \\
& 32 & 69.37 & 28.14 \\
Final NP & & & \\
Final P & 40 & 93.55 & 15.80 \\
\hline
\end{tabular}

Next, the data were analyzed using analysis of covariance (ANCOVA). ANCOVA is a general linear model which blends analysis of variance (ANOVA) and regression analysis. ANCOVA evaluates whether the means of a dependent variable (DV), in this study, the exam scores (fall semester scores and spring semester scores), are equal across levels of a categorical independent variable (IV) often called a treatment, which in this study was class membership (non-proctored exam students, proctored exam students), while statistically controlling for the effects of other continuous variables that are not of primary interest, known as covariates (CV) or nuisance variables, which in this study was student GPA. Mathematically, ANCOVA decomposes the variance in the DV into variance explained by the CV(s), variance explained by the categorical IV, and residual variance. Intuitively, ANCOVA can be thought of as adjusting the DV by the group means of the CV(s) (Keppel, 1991). The results indicate that, controlling for GPA, all exam average score differences were significant, except for Exam 3 ( $p=0.41$ ). Therefore, the research question was supported by all exam results, except for Exam 3. Similar to all 
exams, the average for Exam 3 was lower in the proctored group, however, the differences between the proctored group and the non-proctored group were not significant (see Tables 2-6).

TABLE 2

ANCOVA OF BETWEEN-SUBJECTS EFFECTS FOR EXAM 1 DEPENDENT VARIABLE: EXAM 1 FS

\begin{tabular}{|c|c|c|c|c|c|}
\hline Source & $\begin{array}{l}\text { Type III } \\
\text { Sum of } \\
\text { Squares }\end{array}$ & df & Mean Square & $\mathrm{F}$ & Sig. \\
\hline Corrected model & $14683.24^{*}$ & 2 & 7341.62 & 12.67 & .00 \\
\hline Intercept & 1724.99 & 1 & 1724.99 & 2.97 & .09 \\
\hline GPA FS & 5603.06 & 1 & 5603.06 & 9.67 & .00 \\
\hline Class membership & 9011.78 & 1 & 9011.78 & 15.55 & $* * .00$ \\
\hline Error & 39978.03 & 69 & 579.39 & & \\
\hline Total & 431084.00 & 72 & & & \\
\hline Corrected Total & 54661.27 & 71 & & & \\
\hline
\end{tabular}

TABLE 3

ANCOVA OF BETWEEN-SUBJECTS EFFECTS FOR EXAM 2 DEPENDENT VARIABLE: EXAM 2 FS

\begin{tabular}{|c|c|c|c|c|c|}
\hline Source & $\begin{array}{l}\text { Type III } \\
\text { Sum of } \\
\text { Squares }\end{array}$ & df & Mean Square & $\mathrm{F}$ & Sig. \\
\hline Corrected model & $5963.23 *$ & 2 & 2981.61 & 4.61 & .01 \\
\hline Intercept & 4254.91 & 1 & 4254.91 & 6.58 & .01 \\
\hline GPA FS & 2777.00 & 1 & 2777.00 & 4.29 & .04 \\
\hline Class membership & 3157.72 & 1 & 3157.72 & 4.88 & $* * .03$ \\
\hline Error & 44604.76 & 69 & 646.44 & & \\
\hline Total & 434256.00 & 72 & & & \\
\hline Corrected Total & 50568.00 & 71 & & & \\
\hline
\end{tabular}


TABLE 4

ANCOVA OF BETWEEN-SUBJECTS EFFECTS FOR EXAM 3 DEPENDENT VARIABLE: EXAM 3 FS

\begin{tabular}{|c|c|c|c|c|c|}
\hline Source & $\begin{array}{l}\text { Type III } \\
\text { Sum of } \\
\text { Squares }\end{array}$ & $\mathrm{df}$ & Mean Square & $\mathrm{F}$ & Sig. \\
\hline Corrected model & $13872.38^{*}$ & 2 & 6936.19 & 7.14 & .00 \\
\hline Intercept & 4.63 & 1 & 4.63 & .00 & .94 \\
\hline GPA FS & 13172.37 & 1 & 13172.37 & 13.57 & .00 \\
\hline Class membership & 671.21 & 1 & 671.21 & .69 & $* * .41$ \\
\hline Error & 66972.72 & 69 & 970.61 & & \\
\hline Total & 419784.00 & 72 & & & \\
\hline Corrected Total & 80845.11 & 71 & & & \\
\hline
\end{tabular}

TABLE 5

ANCOVA OF BETWEEN-SUBJECTS EFFECTS FOR EXAM 4 DEPENDENT VARIABLE: EXAM 4 FS

\begin{tabular}{|c|c|c|c|c|c|}
\hline Source & $\begin{array}{l}\text { Type III } \\
\text { Sum of } \\
\text { Squares }\end{array}$ & df & Mean Square & $\mathrm{F}$ & Sig. \\
\hline Corrected model & $12775.73 *$ & 2 & 6387.86 & 10.54 & .00 \\
\hline Intercept & 1530.94 & 1 & 1530.94 & 2.52 & .11 \\
\hline GPA FS & 7802.83 & 1 & 7802.83 & 12.88 & .00 \\
\hline Class membership & 4913.30 & 1 & 4913.30 & 8.11 & $* * .00$ \\
\hline Error & 41784.26 & 69 & 605.56 & & \\
\hline Total & 500128.00 & 72 & & & \\
\hline Corrected Total & 54560.00 & 71 & & & \\
\hline
\end{tabular}

$* \mathrm{R}$ squared $=.23$ (adjusted $\mathrm{R}$ squared $=.21$ )

$* * \mathrm{p}<0.00$ 
TABLE 6

ANCOVA OF BETWEEN-SUBJECTS EFFECTS FOR THE FINAL EXAM DEPENDENT VARIABLE: FINAL FS

\begin{tabular}{|c|c|c|c|c|c|}
\hline Source & $\begin{array}{l}\text { Type III } \\
\text { Sum of } \\
\text { Squares }\end{array}$ & $\mathrm{df}$ & Mean Square & $\mathrm{F}$ & Sig. \\
\hline Corrected model & $16627.35^{*}$ & 2 & 8313.67 & 19.99 & .00 \\
\hline Intercept & 2922.07 & 1 & 2922.07 & 7.02 & .01 \\
\hline GPA FS & 6291.12 & 1 & 6291.12 & 15.13 & .00 \\
\hline Class membership & 10258.89 & 1 & 10258.89 & 24.67 & $* * .00$ \\
\hline Error & 28690.64 & 69 & 415.80 & & \\
\hline Total & 539336.00 & 72 & & & \\
\hline Corrected Total & 45318.00 & 71 & & & \\
\hline
\end{tabular}

\section{CONCLUSION}

This study provided substantial support for the use of proctored versus non-proctored online exams. Furthermore, in order to minimize academic dishonesty, instructors should use proctored exams for their online classes. There may be possible limitations of the research. First, students in the proctored section may have scored lower exam scores due to an increase of anxiety knowing that they were being proctored, versus the minimization or elimination of cheating due to proctoring. It would be rather challenging to control for this possible covariate. Second, there may have been other variables that needed to be controlled. As more instructors conclude that proctored exams are necessary for their online classes, it will be interesting for future research to note if the surge in popularity for online classes plateaus or even declines as a result. Students may be attracted to online classes because of the increased opportunity for academic dishonesty in the case of instructors who do not proctor their exams. In conclusion, there may be fewer or no opportunities for academic dishonesty due to the implementation of proctored online exams. 


\section{REFERENCES}

Anderson, D. R., Sweeney, D. J., \& Williams, T. A. (2009). Essentials of statistics for business and economics, fifth edition. Mason, OH: Thomson Higher Education.

Grijalva, T. C., Kerkvliet, J., \& Nowell, C. (2006). Academic honesty and online courses. College Student Journal, 40(1), 180-185.

Harmon, O. R., \& Lambrinos, J. (2008). Are online exams an invitation to cheat? Journal of Economic Education, 39(2), 116-125.

Jones, D. L. R. (2011). Academic dishonesty: Are more students cheating? Business Communication Quarterly, 74(2), 141-150.

Jones, I. M. (2009). Cyber-Plagiarism: Different method - same song. Journal of Legal, Ethical and Regulatory Issues, 12(1), 89-100.

Karim, M. N., Kaminsky, S. E., \& Behrend, T. S. (2014). Cheating, reactions, and performance in remotely proctored testing: An exploratory experimental study. Journal of Business Psychology, $29,555-572$.

Keppel, G. (1991). Design and analysis: A researcher's handbook (third edition). Englewood Cliffs: Prentice-Hall, Inc.

Porter, B. (2015, October). How software helps keep online learners honest. TechCrunch, 15, 1-4.

Simpson, E., \& Yu, K. (2012). Closer to the truth: Electronic records of academic dishonesty in an actual classroom setting. Ethics \& Behavior, 22(5), 400-408. 